\title{
Análise da Variação Populacional e os Impactos no Desenvolvimento da Associação dos Municípios do Oeste de Santa Catarina - Amosc
}

\author{
Analysis of Population Variation and the \\ Impacts in Development of the Association of \\ Counties of West of Santa Catarina - Amosc
}

\author{
Rógis Juarez Bernardy ${ }^{1}$ \\ Augusto Fischer ${ }^{2}$ \\ Juliana Rammé ${ }^{3}$
}

\section{Resumo}

Uma região possui fenômenos que são particulares em função de sua configuração territorial, espacial, cultural, social e econômica. Neste contexto, esta pesquisa foi centrada na análise da variação demográfica dos 20 municípios que fazem parte da Associação dos Municípios do Oeste de Santa Catarina (Amosc), no período de 1991 a 2010, com base nos dados dos censos demográficos do IBGE e seus impactos no desenvolvimento municipal. Analisaram-se, também, as taxas e variações da população rural, urbana e total espacializadas por intermédio de mapas temáticos. Como resultado observou-se que as variações populacionais foram expressivas, tanto negativas quanto positivas, o que demonstra que a Amosc possui uma tendência de retração (esvaziamento de municípios periféricos) e concentração (em cidade de porte médio como Chapecó e junto ao eixo rodoviário). Os conhecimentos desta pesquisa orientam as políticas públicas estratégicas direcionadas ao desenvolvimento econômico e social dos respectivos municípios, com diferentes configurações em relação à mobilidade de suas populações.

Palavras Chave: Desenvolvimento. Região e mobilidade populacional.

1 Graduado em Geografia (UFSM), mestre em Cadastro Técnico Multifinalitário (UFSC) e doutor em Cadastro Técnico Multifinalitário e Gestão Territorial (UFSC). Professor da Universidade do Oeste de Santa Catarina (Unoesc). rjbernardy@gmail.com

2 Graduado em Administração (UnC), mestre em Engenharia de Produção e Sistemas (UFSC) e doutor em Administração (USP). Professor da Universidade do Oeste de Santa Catarina (Unoesc). augusto.fischer@unoesc.edu.br

3 Graduada em Arquitetura(Unochapecó), especialista em Levantamentos Geodésicos em georreferenciamento de imóveis rurais (Unochapecó). Mestranda em Cadastro Técnico Multifinalitário (UFSC). julianaramme@yahoo.com.br 


\begin{abstract}
A region has phenomena that are individuals in function of his territorial, space, cultural, social and economical configuration. In this context, this research was focused on analyzing the demographic variation, of the twenty counties that make part of the Association of the Counties of the West of Santa Catarina (Amosc), in the period from 1991 to 2010, on basis of the data of the demographic censuses, of the IBGE and his impacts in the municipal development. Also, there were analysed the rates and variations of the rural, urban, and total population espatialized through thematic maps. As results, was observed that the population variations were expressive, both negative and positive, which shows that the Amosc has a tendency to decrease (depletion of peripheral counties) and concentration (in medium-sized city like Chapecó and next to the road). The knowledges of this research guide to public strategic policies aimed to the economic and social development of their respective municipalities, with different configurations regarding the mobility of their populations.
\end{abstract}

Keywords: Development. Region and population mobility. 
Os estudos que contemplam a região são importantes, uma vez que permitem uma análise detalhada do fenômeno pesquisado, neste caso vinculado à evolução e perspectivas da dinâmica populacional e o desenvolvimento na Associação dos Municípios do Oeste de Santa Catarina (Amosc), regionalização instituída no âmbito estadual a partir da década de 60 .

Os municípios da Amosc tiveram um processo de ocupação e integração ao modelo de produção capitalista tardio e incompleto, representado pela inserção de grupos étnicos oriundos principalmente do Rio Grande do Sul na primeira metade do século 20, que desenvolviam atividades econômicas essencialmente agropecuárias.

Neste contexto, em menos de um século, as atividades e os grupos sociais que se ampliaram e criaram novas formas de uso do solo na região sofreram um processo de estabilização e inclusive retração, refletindo na continuidade do crescimento das cidades, nas próprias atividades econômicas rurais, e, portanto, no desenvolvimento dos municípios.

Nos procedimentos metodológicos, a escala temporal contemplou 29 anos, de 1991 a 2010, com base em dados dos censos demográficos do IBGE, a espacialização de dados e análises que permitem compreender a essência da problemática da pesquisa e seus reflexos em processos de desenvolvimento endógeno dos municípios, com base em indicadores relacionados à variação populacional rural, urbana e total.

Como principal resultado evidencia-se que as variações populacionais foram expressivas, tanto negativas quanto positivas, o que demonstra que a Amosc possui uma tendência de retração (esvaziamento de municípios periféricos) com bases populacionais mínimas e concentração em uma única cidade de porte médio. 
Os conhecimentos desta pesquisa servem de suporte para a orientação de diferentes políticas públicas estratégicas em âmbitos institucionais, direcionadas à gestão do desenvolvimento econômico e social dos respectivos municípios, para que tenham progressividade em seus níveis de desenvolvimento.

Além desta seção introdutória, o presente artigo apresenta, na segunda seção, uma revisão teórica sucinta das dinâmicas territoriais regionais, e discorre também sobre a contextualização histórica da Amosc. A terceira seção descreve os procedimentos metodológicos utilizados no estudo. Na quarta seção são apresentados e discutidos os resultados da pesquisa, e na quinta seção são expostas as conclusões e considerações finais do estudo.

\section{Dinâmicas Territoriais Regionais}

$\mathrm{Na}$ análise regional deve-se considerar a continuidade da manifestação dos fenômenos geográficos sobre o território, inclusive observando a sua ocorrência em períodos pretéritos, o que permite efetivar comparativos, inclusive com fenômenos similares, na atualidade. Neste enfoque, este referencial bibliográfico, num primeiro momento, abordou as discussões acerca da região, e, no segundo, as variáveis relacionadas aos aspectos dos processos históricos e socioespaciais que contemplem a população da Amosc.

Embora a conceituação de região remeta a certa similaridade na sua organização histórica, cultural, social, econômica, a área desta pesquisa está fortemente influenciada por decisões exógenas à região, especialmente em relação à mobilidade populacional, o que demonstra os vínculos territoriais locais com outras regiões instaladas no ambiente dos municípios. Neste contexto, para Santos (2006, p. 14), “o espaço é o resultado das ações do homem sobre os próprios espaços intermediados pelos objetos naturais ou artificiais, que o autor chama de segunda natureza e que sofrem diferentes interferências em função das ações humanas”. 
Ao considerar as distintas temporalidades na utilização do território do Oeste Catarinense, é possível identificar determinadas especificidades em relação aos processos de artificialização da paisagem regional, com base em que Bavaresco (2005) chama de ciclos econômicos. Estes se manifestaram no território da Amosc, como a pecuária, a erva-mate, a madeira e a agroindústria, e se reproduziram em forma de ciclos (período em que predomina determinado fenômeno, neste caso econômico e social).

Recentemente, a estes ciclos se acrescenta o aproveitamento energético por meio de instalação de usinas hidrelétricas em cursos d'água de diferentes portes, primeiramente centradas no Rio Uruguai, que determinam importantes impactos sociais nas áreas de entorno dos reservatórios (decisões exógenas). Temporalmente a coexistência de elementos da paisagem em determinado lugar, somada a uma maior uniformidade na organização e distribuição dos mesmos, quando comparada ao ambiente externo que conforma uma "diferenciação das áreas" (particularidades), pode ser chamada de região.

Tradicionalmente no ambiente desta pesquisa, a combinação de processos econômicos está vinculada à motivação de novas dinâmicas espaciais, que modelam os usos do solo tanto no espaço rural quanto urbano, mesmo em áreas com processos de desenvolvimento desigual (como exemplo, no espaço rural, centro e periferia urbana), não geográfico, entretanto social.

Em conformidade com Becker (2003), os distintos processos de desenvolvimento regional não são iguais, uma vez que se constituem de movimentos contrários, fortemente influenciados por fatores exógenos e também por reações endógenas, ou seja, de dentro para fora, de acordo com as mobilizações de agentes de desenvolvimento locais.

Nos municípios da Amosc a combinação de processos econômicos determinou uma geografia com especificidades próprias quanto à mobilidade populacional, pois os processos de urbanização são dispersos, o que determina uma acentuada mobilidade populacional regional e extrarregional, 
com forte tendência de retração dos contingentes em locais periféricos, que condicionam os processos desiguais de (des)envolvimento autônomos em período vindouro.

A Amosc teve um processo de ocupação que precedia aos imigrantes descendentes de europeus, oriundos do Rio Grande do Sul, em áreas de colonização induzida, representado pelos grupos de guarani, kaingang, caboclos e fazendeiros que possuíam organizações sociais distintas. A base de sustentação destes grupos era o nomadismo e a produção da pecuária bovina, respectivamente (Werlang, 2002). Os caboclos aproveitavam os recursos disponíveis pela natureza como a caça, a pesca e a coleta de frutas silvestres, aliado a uma incipiente agricultura rotativa (roça), desenvolvida próximas das residências e dos cursos d'água, sem a preocupação com uma divisão territorial em propriedades.

Embora se tenha o hábito de observar a história da ocupação territorial da Amosc de forma fragmentada e em fases sucessivas, foi importante a relação de suporte que os grupos de indígenas proporcionaram para a efetividade do "branqueamento" da região. Os índios “[...] foram desbravadores e guias dos colonizadores, ensinavam-lhes o cultivo e o uso de várias espécies de vegetais, como o milho, a mandioca, a erva-mate e a domesticarem os animais" (Lisboa, 2003, p. 4).

A inserção de novos grupos sociais aconteceu a partir da sobreposição aos grupos anteriores e não por fases sucessivas. As mesmas foram acompanhadas pela periferização geográfica dos índios e dos caboclos, inclusive em termos cultural, social e econômico, uma vez que foram confinados em espaços sem aptidão para as atividades da extração vegetal, da agricultura e da pecuária, evidenciando a segregação étnica na ocupação territorial do Oeste Catarinense. Renk (1999) chama este fenômeno de "deslocamento compulsório, isto é, não voluntário, entretanto obrigatório". 
Por volta da metade da segunda década do século 20 houve uma divisão administrativa do território do Oeste Catarinense em municípios, quando se formaram duas importantes referências espaciais: o município de Cruzeiro, atual Joaçaba, no Meio Oeste e o de Chapecó, (ambos emancipados em 25 de agosto de 1917), o último com extensão territorial até a fronteira com a Argentina (em torno de $14 \mathrm{mil} \mathrm{km}^{2}$ ) (Prefeitura..., 2011). Estas medidas político-administrativas demonstravam que a região estava apta para imprimir um novo modelo de desenvolvimento, ou seja, a inserção de capital com o apoio do Estado, diferenciado daquele até então difundido e fortemente vinculado ao uso dos recursos naturais.

A organização social dos colonos oriundos do Rio Grande do Sul deu-se com o incentivo das companhias colonizadoras, que tiveram a incumbência de dividir o território em lotes similares em relação ao tamanho da área. Possuíam em torno de 25 hectares e o formato tinha a testada estreita e o fundo alongado (transplante de divisão fundiária utilizada no Rio Grande do Sul, em período anterior) e tinham, principalmente, como limites, os cursos d'água e os próprios divisores ou cotas mais elevadas do relevo, proporcionando um desenvolvimento de sistemas agrários de acordo com as especificidades culturais do grupo e das potencialidades da geografia (Werlang, 2002).

Para Werlang (2002, p. 34), "o travessão dividia pelo meio as terras existentes entre dois cursos d'água, sendo que as terras eram divididas em lotes de 25 a 35 hectares, de acordo com as restrições do relevo e a existência de cursos d'água". Este modelo de divisão da terra foi importante, pois determinou um confinamento social de famílias com expressivo número de membros nas propriedades e que posteriormente foi essencial para a formação de processos de mobilidade regional (especialmente de jovens migração especializada).

A produção do espaço rural deu-se com as atividades econômicas no interior das propriedades que desconsideravam as formas naturais da paisagem. A partir da progressividade econômica e a formação das primeiras vilas compostas basicamente pela serraria, pela igreja, pelo ínfimo comércio, 
pela escola e por algumas casas, no entanto, houve a troca do uso do solo do extrativismo para o ambiente urbano, caracterizado por incipientes atividades econômicas típicas de cidades, embora dispersas pelo território.

A partir da segunda metade do século 20, "houve a reestruturação do espaço da região da Amosc para o modelo agroindustrial, sendo que a indústria alimentícia passou a organizar o território" (Bavaresco, 2005, p. 12). Difundida em grupos sociais dominantes no território que não distinguia a identidade econômica dos produtores (colonos), esse modelo posteriormente se tornou seletivo, e foi fundamental para a ampliação de uma urbanização concentrada e dispersa.

As áreas rurais, que tinham processos produtivos específicos ao incorporar as novas formas de produção, com a instituição de tecnologias na produção de matéria-prima para agroindústria, liberaram expressivos contingentes populacionais para os centros urbanos. Esse fato acarretou o esvaziamento espacial de parte do espaço rural e gerou a descontinuidade e a ruptura nas formas de produção (Silvestro et al., 2001), resultando nos processos de descontinuidade na sucessão das propriedades rurais que se processam até a atualidade (Wanderley, 2000).

Especificamente na Amosc, as mobilidades regionais estão associadas essencialmente "às mudanças na estrutura agrária (seletividade do trabalho nas atividades econômicas rurais e concentração fundiária) e na diversidade econômica da cidade da região (Chapecó)" que exerce uma atração sobre a população regional, vinculada à estagnação das relações de trabalho no espaço rural ante a modernização do sistema de produção agroindustrial (suinocultura e avicultura) (Pacheco apud Lisboa, 2008).

Às motivações das migrações acrescentam-se as expectativas de melhoria de acesso, a diversificação e a qualidade do trabalho e de vida, o acesso ao ensino especializado, e, portanto, a difusão de informações e conhecimentos, os novos laços sociais, o acesso à saúde pública, entretenimento, entre outros. 
Desta forma, o espaço regional pode ser evidenciado pela dinâmica populacional e as respectivas particularidades que se estruturam a partir das inter-relações entre os municípios da região da Amosc que apresentam diferentes especificidades. O processo de ocupação e integração econômica e estagnação dos municípios da Amosc, no Oeste Catarinense, do ambiente rural e de determinadas cidades de pequeno porte, possui um ciclo reduzido, uma vez que este intervalo temporal (ocupação e esvaziamento) vem ocorrendo há menos de um século, podendo persistir por mais algumas décadas e possui importantes impactos no desenvolvimento e na continuidade dos próprios municípios.

Assim, no âmbito regional existe um quadro de instabilidade em relação à progressividade do desenvolvimento, tanto rural quanto urbana (mais especializada) e inibição da instalação e ampliação de (novos) empreendimentos, pela migração especializada que tende a cristalizar um ambiente economicamente mais homogêneo, portanto menos diversificado e autônomo.

\section{Contextualização Histórica da Amosc}

A Amosc foi a terceira Associação de Municípios do Estado de Santa Catarina que, na atualidade, apresenta 21 Associações, com uma formação inicial que abrangia 34 municípios do Oeste Catarinense. Esta sofreu ao longo do seu percurso histórico um processo de divisão municipal tanto pela formação de novos municípios (interna) quanto pela criação de duas novas Associações (externas) (Bernardy; Zuanazzi; Monteiro, 2008).

Atualmente, a Amosc congrega os municípios de Águas de Chapecó, Águas Frias, Caxambu do Sul, Chapecó, Cordilheira Alta, Coronel Freitas, Formosa do Sul, Guatambu, Irati, Jardinópolis, Nova Erechim, Nova Itaberaba, Pinhalzinho, Planalto Alegre, Quilombo, São Carlos, Santiago do Sul, Serra Alta, Sul Brasil e União do Oeste. Conjuntamente, estes municípios abrangem uma área territorial de $2.955 \mathrm{~km}^{2}$ (Amosc, 2011). 
A base da formação territorial dos municípios da Amosc provém da área original de Chapecó, que teve seu processo de emancipação em 1917. O primeiro desmembramento de município, que viria posteriormente compor a Amosc, ocorreu em 1953 (36 anos após a autonomia política de Chapecó) com a criação do município de São Carlos. Na década de 60, houve expressiva divisão municipal: Coronel Freitas, Quilombo e Pinhalzinho em 1961, Águas de Chapecó e Caxambu do Sul em 1963 e Nova Erechim em 1964.

A regionalização da Amosc (Mapa 1) está vinculada às ações de um órgão prestador de serviços em projetos, consultoria e assessoramento técnico municipal, tanto do poder executivo quanto do legislativo, consórcios intermunicipais, convênios, reivindicações regionais, estímulo e promoção do intercâmbio técnico-administrativo, entre outros, considerando que toda a estrutura é mantida pelos municípios integrantes da Associação (Amosc, 2011).

Mapa 1 - Localização dos Municípios da Amosc em Santa Catarina

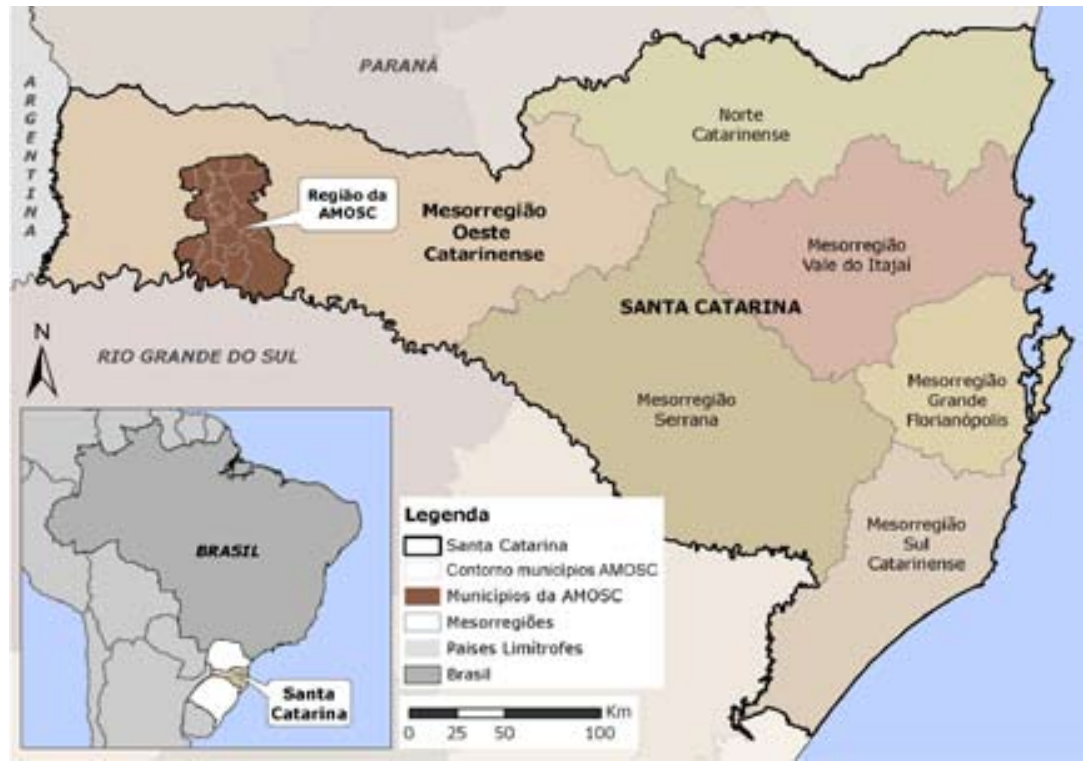

Fonte: IBGE, 2000a. 


\section{Procedimentos Metodológicos}

Os procedimentos metodológicos estão relacionados aos mecanismos, às técnicas e à sequência lógica empregadas nos processos de pesquisa, vinculados aos objetivos instrumentais que determinam o que foi pesquisado e compreendido. Esta pesquisa foi embasada em informações secundárias, com base em dados do Instituto Brasileiro de Geografia e Estatística (IBGE) em três temporalidades (29 anos): 1991, 2000b e 2010, a partir da base de dados dos censos demográficos na Associação dos Municípios do Oeste de Santa Catarina (Amosc).

Especificamente os dados de interesse da região da Amosc (20 municípios), por temporalidade, foram os seguintes: variação populacional rural de 1991 a 2010; variação populacional urbana de 1991 a 2010 e variação populacional total de 1991 a 2010.

Em relação à abordagem da pesquisa, se enquadra como quantitativa, uma vez que se aproveita da base de dados de informações secundárias do IBGE, que servem de aporte para uma posterior análise. Em relação a este tipo de pesquisa, apresentou a utilização de técnicas estatísticas na estratificação dos dados para a espacialização da cartografia temática regional. Desta forma, a interpretação das informações da dinâmica populacional, com base em critérios objetivos e embasados na realidade regional, permite a verificação da dinâmica populacional regional quanto aos fenômenos vinculados aos dados analisados.

Os resultados obtidos dizem respeito à formação de perspectivas da dinâmica populacional, por município, comparativos de involução e evolução, formação de blocos geográficos com características similares, visíveis com base em cartografia temática regional (com respectiva análise dos mapas), estratificadas de acordo com o tamanho populacional e vínculo com o desenvolvimento municipal. 


\section{Análise Populacional Regional}

No ano de 1991 apenas 10 municípios da Amosc já haviam sido constituídos, e os demais foram emancipados no período imediatamente após a esta série de dados do IBGE. Observa-se que entre 1991 e 2000 todos os municípios constituídos perderam população rural motivados por três fatores regionais: o êxodo rural, o aumento de perímetros urbano e as próprias emancipações. As variações populacionais rurais negativas oscilaram de $-34,88 \%$ (- 13.924 pessoas) em Chapecó (perda de distritos que se emanciparam) até -11,84 em Caxambu do Sul (êxodo rural). No ano de 1991, a maior taxa de população rural era de União do Oeste $(91,93 \%)$ e a menor de Chapecó $(21,37 \%)$.

Mapa 2 - População Rural em 1991, 2000 e 2010 na Amosc
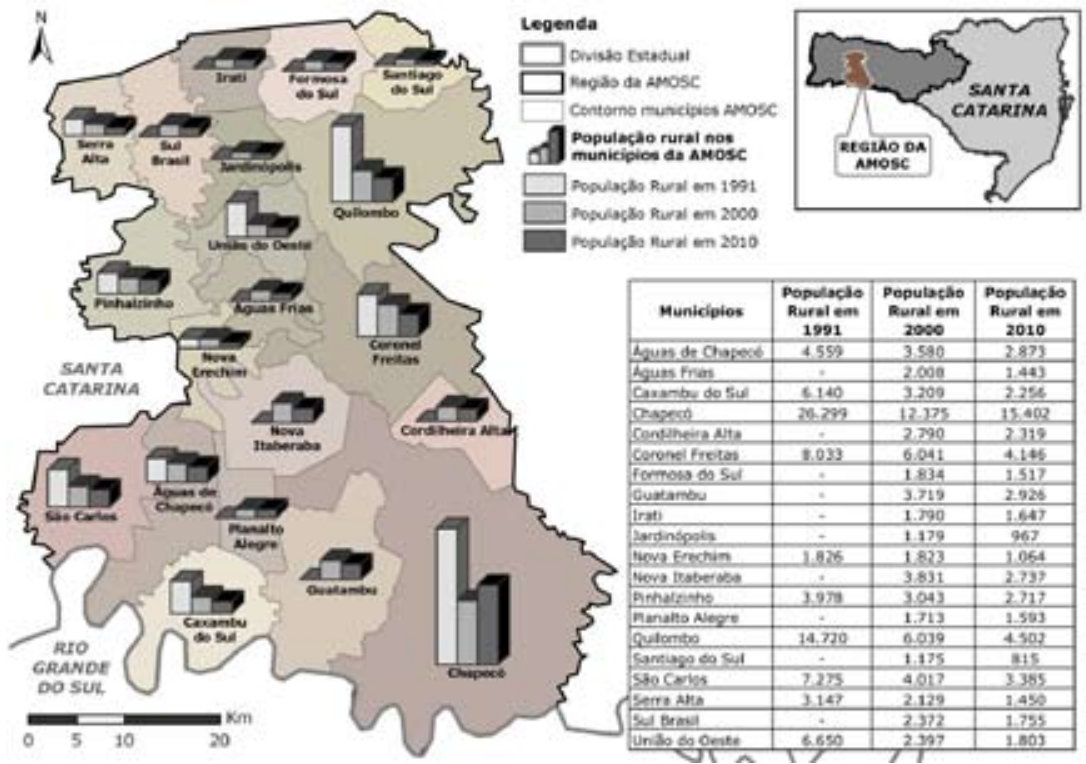

Fonte: IBGE, 1991, 2000b e 2010. 
Até o ano de 2000, todas as unidades administrativas da Amosc já estavam definidas e consolidadas, o que permite uma análise em diferentes temporalidades do conjunto da população rural de todos os municípios. Neste caso, o maior percentual de população rural era de Cordilheira Alta $(90,20 \%)$ que se emancipou de Chapecó, com núcleo urbano reduzido. O menor percentual de população rural era de Chapecó e representava apenas $8,42 \%$, embora se deva considerar que em termos absolutos atingia 12.375 habitantes, ou seja, a maior população rural da Amosc (todos os demais municípios possuíam a população total menos expressiva).

No intervalo entre 2000 e 2010 (IBGE) houve uma redução na população absoluta rural em todos os 20 municípios, exceto em Chapecó (em função do expressivo crescimento urbano). A diminuição da população rural foi determinada principalmente pela mobilidade populacional intra e extrarregional, conjugada por fatores econômicos da principal matriz produtiva da região (agroindústria). A maior variação negativa relativa da população rural foi de Nova Erechim (- 51,62\%), considerando que este município se localiza no corredor da BR 282, entre as centralidades de Chapecó e Pinhalzinho. Na região da Amosc é muito importante o papel desempenhado pela cidade central, uma vez que possui uma atratividade considerável sobre todos os demais municípios da região, inclusive do norte do Rio Grande do Sul.

Em relação à participação da população rural no contexto geral, a maior participação relativa é de Irati (78,58\%). De forma geral, observa-se uma queda nos percentuais da população rural e também na população absoluta, em função da estabilização e retração da população geral, determinada pelas quedas nas taxas de natalidade e pela expressiva mobilidade para outras regiões do próprio Estado de Santa Catarina, principalmente da Grande Florianópolis e Vale do Itajaí.

A distribuição da população no espaço rural tem implicância direta com a localização da população urbana, posto que, em função das principais identidades econômicas da região (rural), os municípios se constituem com processos de urbanização recentes e incompletos. Em 1991, dos dez muni- 
cípios, as taxas de urbanização eram ínfimas, exceto em Chapecó e Pinhalzinho (ambas cidades localizadas no eixo da BR 282), que apresentavam uma urbanização mais completa no que diz respeito à diversidade de atividades econômicas e serviços públicos e ao tamanho populacional.

Mapa 3: População Urbana em 1991, 2000 e 2010 na Amosc

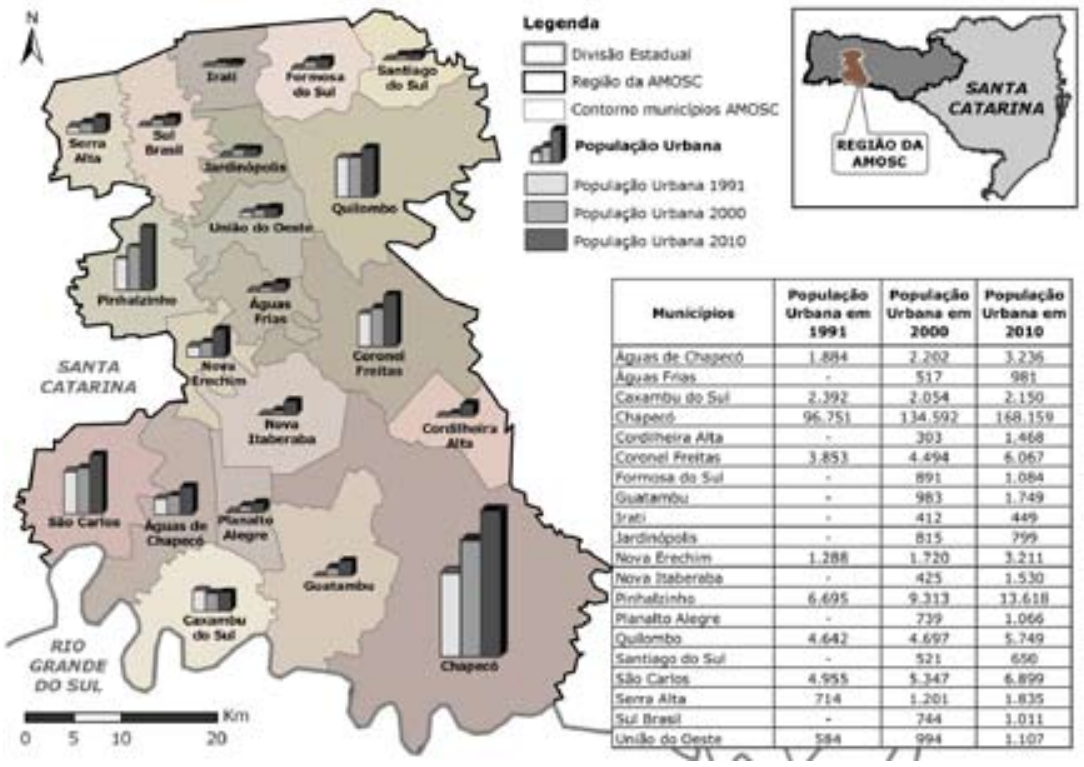

Fonte: IBGE, 1991, 2000b e 2010.

No intervalo entre 1991 e 2000, as taxas de urbanização foram progressivas e refletiu o processo pós-emancipatório e a instalação das estruturas administrativas, que passou a se constituir na principal forma de acesso ao trabalho por meio do serviço público. Este possibilitou a canalização de renda no comércio local, juntamente com a renda da agropecuária, e esta realidade continua idêntica na atualidade.

No ano de 2000, 55\% dos municípios da Amosc possuíam tamanhos populacionais que não atingiam mil habitantes urbanos, o que demonstra que estes municípios foram constituídos com núcleos populacionais redu- 
zidos (a menor taxa de urbanização era de Cordilheira Alta, com apenas $9,8 \%$ da população total). A maior taxa de urbanização, neste período, foi evidenciada em Chapecó, que atingiu 91,58\%, em parte reflexo de uma economia alicerçada na indústria, no comércio e nos serviços, com uma expressiva capacidade de atrair pessoas da região, além de apresentar taxas de natalidade acima da média regional (2,8\%, segundo dados do IBGE, 2000b). Acrescenta-se a estes fatores a ampliação do perímetro urbano, uma vez que a área territorial da cidade se dilata em função de uma urbanização horizontal e descontínua.

Em relação à variação populacional urbana de 2000 para 2010, destacam-se dois municípios: Cordilheira Alta (variação positiva de 295,51\%) e Nova Itaberaba (variação positiva de 258,96\%). Embora se reconheça que são municípios com população reduzida, possuem uma urbanização motivada por dois fatores: forte influência da proximidade da cidade de Chapecó (custo da terra para moradia é mais barata) e proximidade com a BR 282 (localização de atividades industriais), espaço preterido para a instalação econômica pelo corredor rodoviário entre países.

As taxas de urbanização de 2010, segundo o IBGE, são variáveis e Chapecó possuía 91,61\% da população na cidade, seguido de Pinhalzinho, com 83,37\%. Dos municípios da Amosc, 60\%, entretanto, possuíam taxas de urbanização inferiores a 50\%, e pela estabilização e retração populacional dos mesmos, inclusive no espaço urbano, estas taxas também tendem a ser estáveis ou regressivas (menor taxa de urbanização era de Irati, com apenas $21,42 \%$ ). Independente do tamanho populacional do município, a maior diversidade de atividades econômicas tende a ser urbana. Isso demonstra as dificuldades dos municípios na motivação de trabalho e renda, com base em atividades não rurais. Nestes casos, as atividades urbanas ficam restritas quase que essencialmente aos serviços públicos (prefeituras municipais).

Além da análise detalhada da configuração espacial da distribuição da população entre rural e urbano, é fundamental a compreensão da localização da população total tanto em termos de variação quanto da absoluta, 
uma vez que os territórios possuem diferentes caracterizações, portanto uma distribuição não homogênea (concentrada e dispersa), conforme demonstra o Mapa 4.

Mapa 4 - População Total em 1991, 2000 e 2010 na Amosc

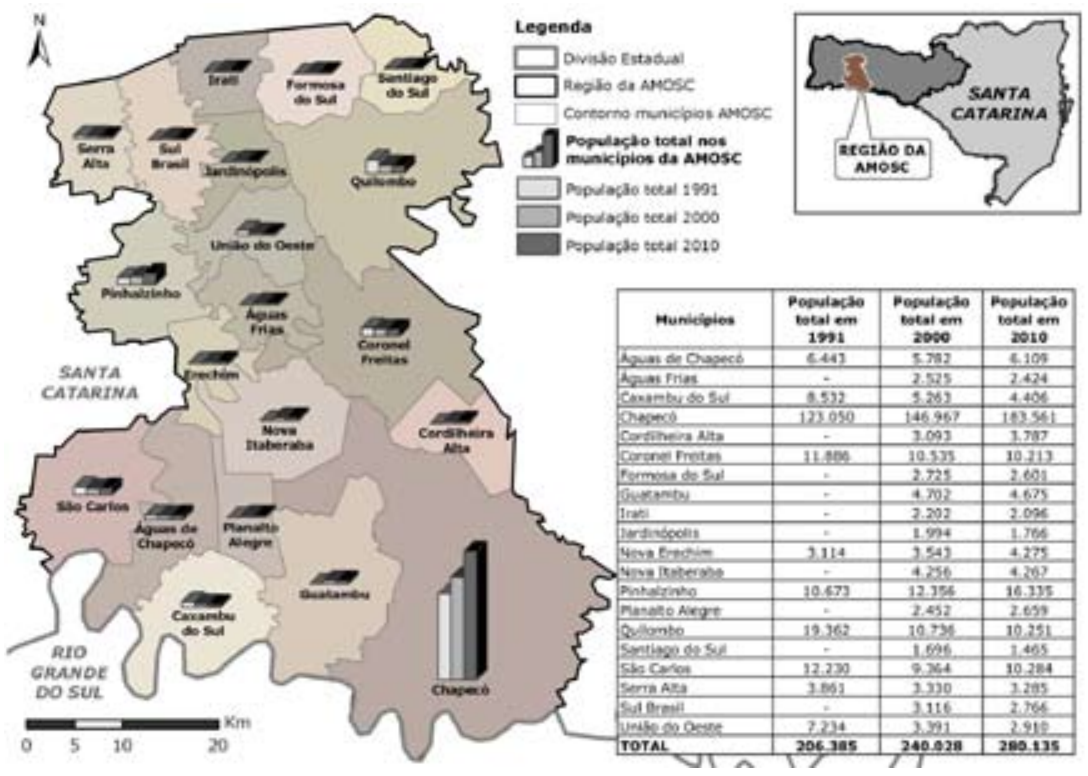

Fonte: IBGE, 1991, 2000b e 2010.

A variação populacional de 1991 a 2000 indica, por um lado, que os dez municípios da região da Amosc já possuíam uma tendência de retração; por outro existia um aumento, como em Chapecó e Pinhalzinho. Neste intervalo foram muito importantes as emancipações para as variações negativas das unidades administrativas, pelo fato de terem perdido parte de seus territórios (distritos). No ano de 1991, a população total dos dez municípios atingia 210.307 habitantes, com 48\% pertencentes ao município de Chapecó.

No ano de 2000 a população dos 20 municípios, com a estabilização nos processos de formação de novos municípios, aumentou para 240.028, ou seja, uma variação positiva de $12,38 \%$. Este aumento, entretanto, ocorreu 
em apenas oito municípios, uma vez que os demais tiveram retrações no conjunto total da população. No intervalo entre 2000 e 2010, a população total dos 20 municípios atingiu 280.135 habitantes, ou seja, uma variação positiva de 14,31\%. O maior acréscimo relativo deste intervalo (2000 a 2010) foi de Pinhalzinho, seguido de Chapecó, Coronel Freitas (estas três concentram as maiores cidades da região) e Nova Erechim.

A variação populacional entre 2000 e 2010 indica que $60 \%$ dos municípios tiveram retração populacional, e se inferem três motivos principais: taxas de natalidade próximas de zero; o forte processo de mobilidade populacional regional (emigração) de municípios como União do Oeste, Sul Brasil, Santiago do Sul e Jardinópolis, localizados ao norte da região; a mobilidade pela formação de reservatório de hidrelétrica (Foz do Chapecó, edificada entre 2008 e 2010) para município junto a margem do rio Uruguai (Caxambu do Sul), que causou expressivo impacto na dinâmica da população ribeirinha.

Observa-se um desequilíbrio em relação à localização da população. Embora os municípios possuam áreas territoriais diferenciadas e dinâmicas econômicas próprias, existe uma forte tendência da ampliação da participação de Chapecó, no seu espaço urbano, na espacialização da população regional, uma vez que as características rurais desde município não se diferem dos demais da região. Assim sendo, a polarização principal da região da Amosc acontece apenas pela cidade de Chapecó e não pelo município (concentra 65,52\% da população da Amosc). Desta forma, a cidade de Chapecó e não o município exerce a função da centralidade regional.

A análise dos dados da dinâmica populacional da região da Amosc evidencia um desequilíbrio em relação a sua localização, uma vez que, por um lado, gera o esvaziamento dos municípios, inclusive a estabilização urbana que deve evoluir para retração, o que compromete a continuidade das atividades produtivas e rompe as relações sociais e, por outro, os municípios (cidades) que abrigam estas populações geram demandas públicas que são regionais, principalmente no acesso à saúde pública, educação e segurança. 


\section{Conclusão}

Na temática principal desta pesquisa verificou-se a evolução populacional rural, urbana e total de 1991 a 2010 e as suas perspectivas, com base em dados censitários do IBGE por meio de estratos e mapas temáticos na Associação dos Municípios do Oeste de Santa Catarina.

Observou-se que as retrações populacionais rurais são importantes, e esta configuração é determinada por problemas estruturais e econômicos que tendem a tornar a região mais homogênea em termos econômicos (atividades econômicas menos diversificadas e concentração da terra) e populacionais (adultos e idosos).

Quanto às taxas de urbanização, são crescentes e diversificadas, e tendem a ser pequenas e estáveis em municípios com população reduzida ou elevada em município-polo ou com atividades econômicas mais centradas e diversificadas na área urbana. Pela trajetória normal, os pequenos municípios tendem a sofrer processos de retração urbana no futuro próximo, inclusive deve gerar comprometimento na continuidade dos mesmos.

Constatou-se que o fenômeno da mobilidade promove a formação de territórios com especificidades próprias, sendo representados pela ampla tendência de esvaziamento, envelhecimento populacional, estabilização e retração urbana, exceto no município mais dinâmico em termos econômicos e populacionais.

No contexto do desenvolvimento da região existe a necessidade de aporte de políticas públicas articuladas (suporte exógeno) e de investimentos em municípios de pequeno porte e com economia pouco diversificada, seja em infraestrutura, em formação profissional e em incentivo à formação de novas cadeias produtivas para a reversão do cenário de estabilização e retração da população regional.

\section{Referências}

AMOSC. Associação dos Municípios do Oeste de Santa Catarina. 2011. Municípios da Associação. Disponível em: <www.amosc.org.br/municípios>. Acesso em: 23 ago. 2011. 
BAVARESCO, P. R. Ciclos econômicos regionais: modernização e empobrecimento no extremo Oeste Catarinense. Chapecó: Argos, 2005.

BECKER, D. F. A economia política do (des)envolvimento regional contemporâneo. In: ; WITTMANN, M. L (Org.). Desenvolvimento regional: abordagens interdisciplinares. Santa Cruz do Sul: Edunisc, 2003. p. 37-66.

BERNARDY, R. J.; ZUANAZZI, J.; MONTEIRO, R. R. Território, planejamento e gestão: um estudo do Oeste Catarinense a partir da região da Amosc. Chapecó: Palotti, 2008.

IBGE. Instituto Brasileiro de Geografia e Estatística. 2000a. Divisão regional. Brasília. Disponível em: <www.ibge.gov.br/home/geociencias>. Acesso em: 17 fev. 2011.

IBGE. Instituto Brasileiro de Geografia e Estatística. 1991. Censo demográfico de 1991. Brasília. Disponível em: <www.ibge.gov.br>. Acesso em: 23 set. 2010.

IBGE. Instituto Brasileiro de Geografia e Estatística. 2000b. Censo demográfico de 2000. Brasília. Disponível em: <www.ibge.gov.br>. Acesso em: 23 set. 2010.

IBGE. Instituto Brasileiro de Geografia e Estatística. 2010. Censo Demográfico 2010: dados preliminares. Brasília. Disponível em: <www.ibge.gov.br>. Acesso em: 24 jan. 2011.

LISBOA, S. S. Os fatores determinantes dos novos movimentos migratórios. In: Revista Ponto de Vista, Universidade Federal de Viçosa, MG, vol. 5. 2008. Disponível em: <http://www.coluni.ufv.br/revista>. Acesso em: 29 ago. 2011.

LISBOA, T. K. Gênero, classe e etnia: trajetórias de vida de mulheres imigrantes. Florianópolis: Ed. da UFSC, 2003.

PREFEITURA Municipal de Chapecó. 2011. Dados históricos. Chapecó. Disponível em: <www.chapeco.sc.gov.br>. Acesso em: 6 set. 2011.

RENK, A. Migrações: de ontem e de hoje. Chapecó: Grifos, 1999.

SANTOS, M. A natureza do espaço: técnica e tempo, razão e emoção. São Paulo: Hucitec, 2006.

SILVESTRO, M. L. et al. Os impasses sociais da sucessão hereditária na agricultura familiar. Chapecó Santa Catarina: Epagri/Nead; Ministério do Desenvolvimento Agrário, 2001. CIDADE?

WANDERLEY, M. de N. B. A valorização da agricultura familiar e a reivindicação da ruralidade no Brasil. In: WORLD CONGRESS OF RURAL SOCIOLOGY, 10., Rio de Janeiro, 30 jul. a 5 ago. 2000.

WERLANG, A. A colonização do oeste catarinense. Chapecó: Argos, 2002. 